SECTION 6. Metallurgy and energy.

Gorokhov Vadim Viacheslavovich Student of Orenburg State University, Russia kasperkommunizm@inbox.ru Nosov Pavel Sergeevich Student of Orenburg State University, Russia nosov.pavel@mail.ru

Gorjachev Sergej Veniaminovich

Candidate of Engineering Sciences, assistant professor of Orenburg State University, Russia

\title{
THE AUTONOMOUS POWER INSTALLATION COMBINED PRODUCTION OF ELECTRICITY, HEAT AND COLD IN THE GAS SUPPLY SYSTEM AT STATIONS OF TECHNOLOGICAL GAS DECOMPRESSION.
}

\begin{abstract}
In this article is discussed method of operating the autonomous power installation combined production of electricity, heat and cold in the gas supply system at stations of technological gas decompression.Shows a schematic diagram workflow autonomous installation, and a description of gas burner device of infrared helical emitter.

Key words: energy efficiency, energy saving, trigeneration, expander-generator unit, gas burner device of infrared helical emitter, absorption refrigerating machine, secondary energy resources.
\end{abstract}

УДК 62-69;621.574.013-932.2;621.578;62-681;62-684.

\section{АВТОНОМНАЯ ЭНЕРГЕТИЧЕСКАЯ УСТАНОВКА КОМБИНИРОВАННОГО ПРОИЗВОДСТВА ЭЛЕКТРОЭНЕРГИИ, ТЕПЛА И ХОЛОДА В СИСТЕМЕ ГАЗОСНАБЖЕНИЯ НА СТАНЦИЯХ ТЕХНОЛОГИЧЕСКОГО ПОНИЖЕНИЯ ДАВЛЕНИЯ ГАЗА}

\begin{abstract}
Аннотация: В данной статье рассмотрен способ работы автономной энергетической установки комбинированного производства электроэнергии, тепла и холода в системе газоснабжения на станциях технологического понижении давления газа. Приведень принципиальная схема, рабочий прочесс автономной установки; и описание работы газогорелочного устройства инфракрасного спиралеобразного излучателя.

Ключевые слова: энергоэффективность, энергосбережение, тригенерачия, детандер-генераторный агрегат, газогорелочное устройство инфракрасного спиралеобразного излучателя, абсорбчионная холодильная машина, вторичные энергоресурсы.

C повышением уровня технологий и постановкой задачи снижения доли использования невозобновляемых источников энергии в общемировой энергетике, появляется необходимость в создании высокоэффективных способов трансформации и выработки энергии. Традиционное раздельное производство различных видов энергии - малоэффективная технология, связанная с большими экономическими потерями и низким коэффициентом полезного действия. Поэтому в данной статье будет представлен способ работы автономной энергетической установки комбинированного производства электроэнергии, тепла и холода в системе газоснабжения на станциях технологического понижении давления газа (газораспределительных станциях - ГРС и газорегуляторных пунктах - ГРП) [1-3]. На сегодняшний день, подавляющее
\end{abstract}


большинство ГРС и ГРП осуществляют процесс понижения давления за счёт дросселирования потока газа, в результате чего теряется колоссальное количество энергии. Далее, нами будет рассмотрена данная установка, её составляющие, способ работы и возможный вариант внедрения в технологическую схему производства.

Производство всех трёх видов энергии реализуется за счёт составляющих автономной энергетической установки:

- детандер-генераторный агрегат (ДГА) с подогревом газа перед детандером[4-7];

- газогорелочное устройство инфракрасного спиралеобразного излучателя;

- абсорбционная холодильная машина (АБХМ) [8-10].

Принципиальная схема установки представлена на рисунке 1.

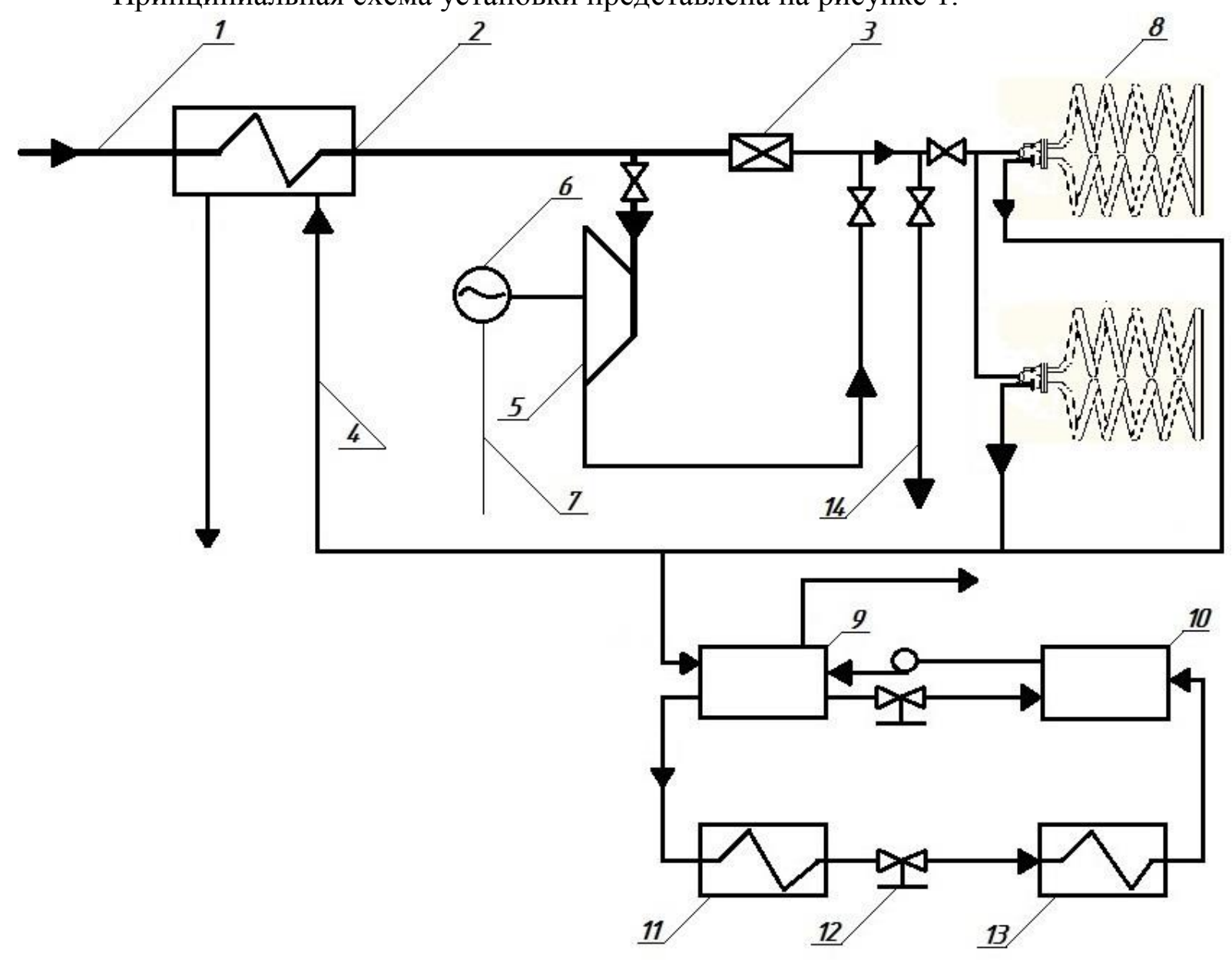

Рисунок 1 - Принципиальная схема.

1 - трубопровод высокого давления, 2 - теплообменник подогрева газа высокого давления, 3 - дросселирующее устройство газопровода, 4 трубопровод с дымовыми газами, 5 - детандер, 6 - генератор, 7 электрическая сеть, 8 - газогорелочное устройство инфракрасного спиралеобразного излучателя, 9 - десорбер, 10 - абсорбер, 11 - конденсатор, 12 - расширительный клапан, 13 - испаритель, 14 - байпасная линия.

Установка работает следующим образом: газ высокого давления 1 поступает в теплообменник 2, куда подводятся дымовые газы 4 от газогорелочного устройства инфракрасного спиралеобразного излучателя 8 для подогрева газа перед детандером 5. В детандере происходит преобразование энергии движущегося потока газа в механическую энергию, а затем в генераторе 6 в электрическую, откуда она по сети 7 поступает к технологическим потребителям. Излишки электрической энергии могут быть предложены для потребления и покрытия нужд близлежащего населенного 
пункта. Также предусмотрено дросселирующее устройство 3, на случай выхода из строя детандера или других составляющих, которое продолжит подавать газ на инфракрасные излучатели с необходимыми параметрами. Далее газ по трубопроводу поступает в инфракрасный обогреватель, где сжигается с целью обогрева производственного помещения. Дымовые газы от процесса сжигания транспортируются по трубе в цех абсорбционной холодильной машины для использования их теплоты с целью выработки холода. Хладагент испаряется при понижении давления в испарителе 13. Этот процесс идет с поглощением теплоты. Процесс понижения давления в испарителе происходит за счет объемного поглощения хладагента жидким абсорбентом в абсорбере 10. Затем абсорбент с поглощенным им хладагентом (бинарный раствор) поступает в десорбер 9. В десорбере бинарный раствор нагревается за счет теплоты дымовых газов, подаваемых к десорберу, в результате чего происходит выделение хладагента из абсорбента. Обедненный абсорбент из десорбера возвращается в абсорбер. Хладагент поступает под большим давлением в конденсатор 11, где переходит в жидкую фазу с выделением теплоты, а затем через расширительный клапан 12 поступает в испаритель, после чего начинается новый цикл.

Обогрев помещений производится с помощью газовой горелки инфракрасного излучения, изображённой на рисунке 2.

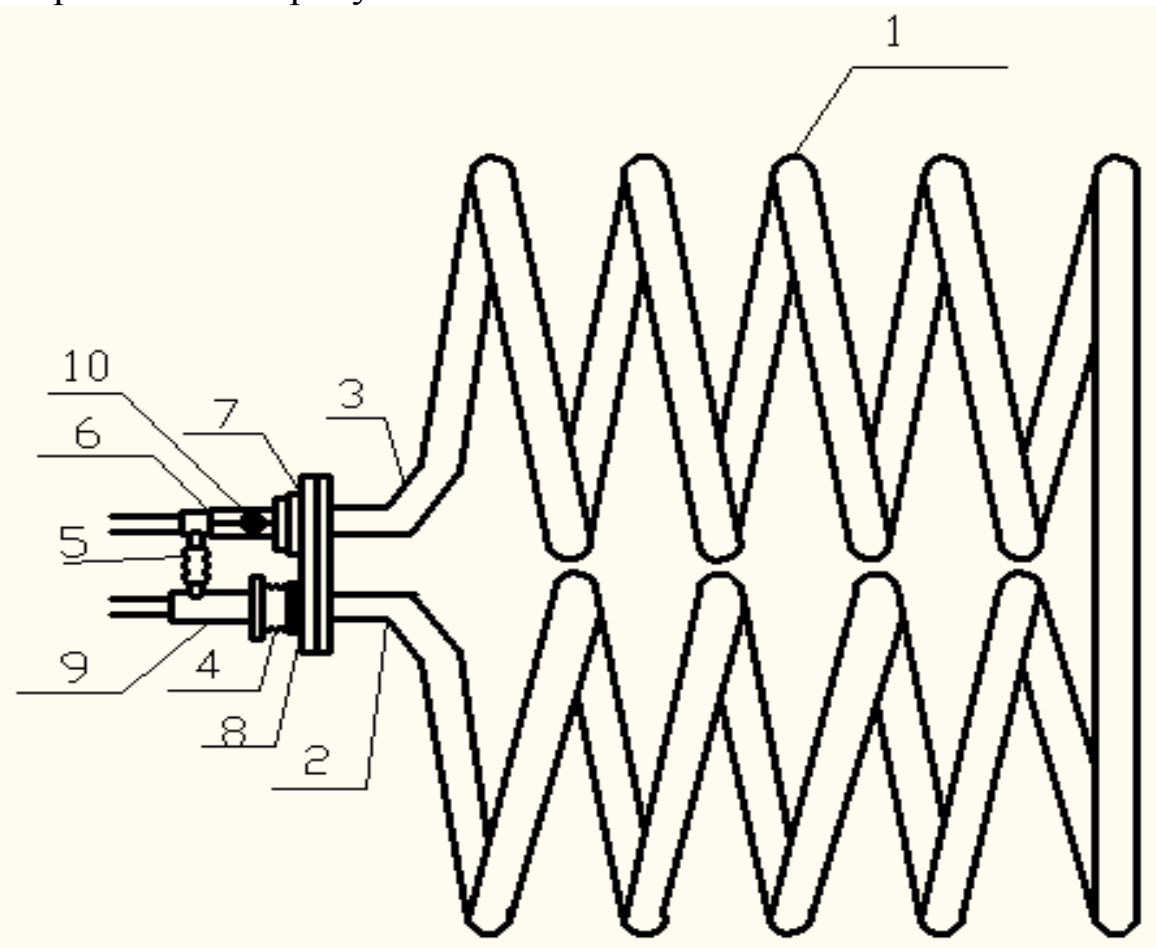

Рисунок 2 - Газогорелочное устройство инфракрасного спиралеобразного излучателя

Предложенное газогорелочное устройство инфракрасного излучателя состоит из спиралеобразной керамической термостойкой радиационной трубы 1 , с горелочной и рекуперативной ветвями 2 и 3 соответственно. На горелочной ветви 2 закреплен сильфон 4, а движение воздуха из рекуперативной части трубы 3 в горелочную часть трубы 2 осуществляется через подвижно-закрепленный сильфон 5. Рекуператор 6 соединен с керамическим корпусом 1 - неподвижно и герметизируется набивным сальником 7. Камера смешения воздуха с газом 9, в которой находится горелка, соединена подвижно с излучающим корпусом 1, при помощи сильфона 4 и набивного сальника 8. 
Газовая горелка инфракрасного излучения работает следующим образом: подаваемый в радиационную трубу газ поступает в камеру смешения 9. Воздух, нагретый в рекуператоре 6 до 400-600 ${ }^{\circ} \mathrm{C}$, через сильфон 5 попадает в камеру смешения природного газа и воздуха 9 . Поступающий в горелку газ загорается при помощи автоматической системы зажигания, и нагревая спиралевидную керамическую поверхность радиационного излучателя 1 до $900{ }^{\circ} \mathrm{C}$, начинает производить инфракрасное тепловое излучение. Отработанные газы, проходя через радиационную трубу 1, нагревают в рекуператоре 6 воздух, который подогреваясь, отправляется в камеру 9. Выхлопные газы удаляются через отверстие 10.

Рассмотренная автономная энергетическая установка комбинированного производства электроэнергии, тепла и холода является универсальным решением в области эффективного энергообеспечения, и в перспективе роста цен на электроэнергию для промышленных производств, экономические показатели аналогичных установок позволят не только производить и устанавливать их в крупных масштабах, но и продолжить процесс усовершенствования текущих технологий.

\section{Литература:}

1. Бестопливные установки для производства электроэнергии, теплоты и холода на базе детандер-генераторных агрегатов. [Электронный ресурс]. URL: http://maxenergy-saving.info/index.php?pg=catalog/54.html (дата обращения 15.01.2014 г.).

2. Способ устойчивого газоснабжения газораспределительной станцией с энергохолодильным комплексом, использующим для выработки электрической энергии и холода энергию избыточного давления природного газа и система для реализации способа (патент РФ № 2346205). [Электронный ресурс]. URL: http://www.freepatent.ru/patents/2346205 (дата обращения 15.01.2014 г.).

3. Технологические схемы систем теплофикации, теплоснабжения и отопления С.А. Чистович, академик РАACH, президент Союза энергетиков Северо-Запада России. АВОК №7, 2007

4. Агабабов В.С., Корягин А.В., Титов В.Л., Михайлов Н.А. О подогреве газа в детандер-генераторных агрегатах // Энергосбережение и водоподготовка.-2001.-№ 1.- C.38-42.

5. АгабабовВ.С., Хаймер Ю.Ю, Утенков В.Ф.,. Получение экологически чистой электроэнергии при утилизации энергии давления транспортируемого природного газа.// Энергосбережение и водоподготовка.-1999.- №4. -С.7-10.

6. Агабабов В.С. Основные особенности применения детандер-генераторных агрегатов на ТЭЦ // Энергосбережение и водоподготовка.-2002.-№ 3.-С.27-29.

7. Агабабов В.С., Галас Н.В., Джураева Е.В., Зройчиков Н.А., Корягин А.В. Сравнение различных способов подогрева газа в детандер-генераторном агрегате // Теплоэнергетика 2003 .-№11. -С.46-50.

8. СОЛОВЬЕВ Р.В. ОПРЕДЕЛЕНИЕ ЭФФЕКТИВНОСТИ ДЕТАНДЕР-ГЕНЕРАТОРНЫХ АГРЕГАТОВ ПРИ ИСПОЛЬЗОВАНИИ ВТОРИЧНЫХ ЭНЕРГЕТИЧЕСКИХ РЕСУРСОВ ПРОМЫШЛЕННЫХ ПРЕДПРИЯТИЙ. Диссертация на соискание ученой степени кандидата технических наук, Москва, 2010 год

9. Абсорбционные холодильные машины - АБХМ. [Электронный ресурc]. URL: $\mathrm{http}: / /$ www.manbw.ru/analitycs/absorbtion_chillers_absorptive_refrigerators-

ABHM.html (дата обращения 15.01.2014 г.).

10. Шилкин Н. В. Абсорбционные холодильные машины. АВОК №1'2008 / Инженерные системы зданий. [Электронный pecypc]. URL: http://www.abok.ru/for_spec/articles.php?nid=3873 (дата обращения 15.01.2014 г.). 